\title{
SCIENCE
}

A WEEKLY JOURNAL DEVOTED TO THE ADVANCEMENT OF SCIENCE, PUBLISHING THE OFFICIAL NOTICES AND PROCEEDINGS OF THE AMERICAN ASSOCIATION FOR THE ADVANCEMENT OF SCIENCE

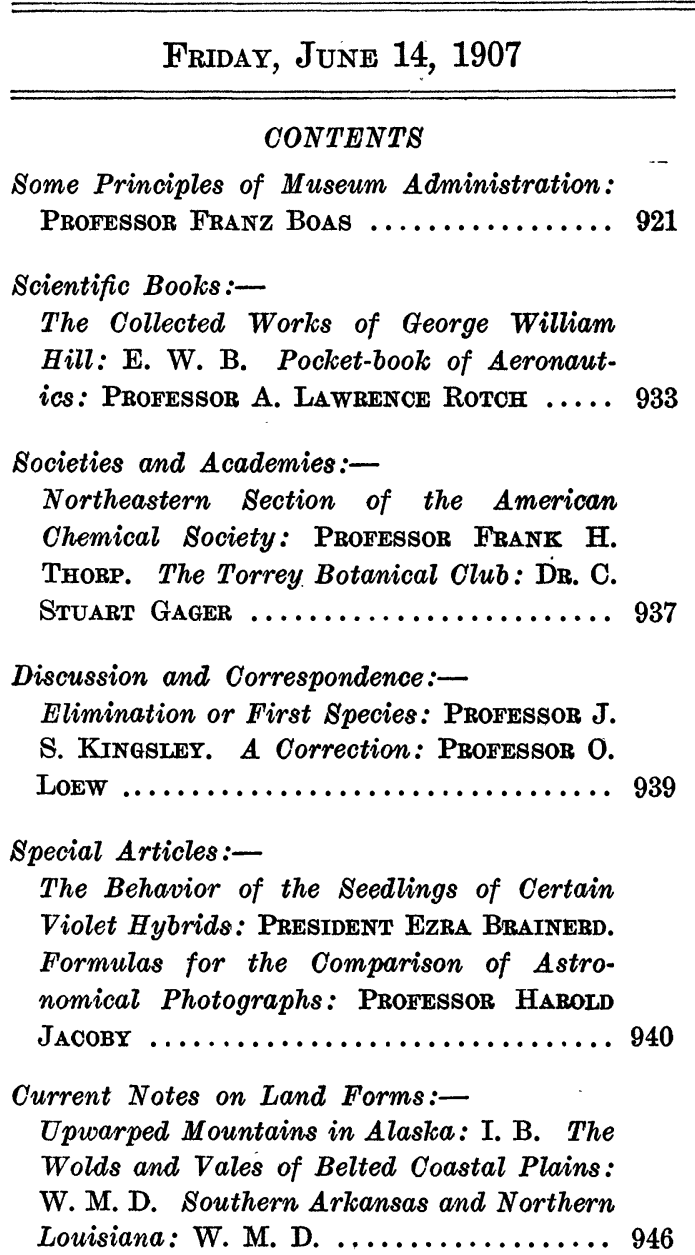

The Bicentenary of Linnous ......... 949

Scientific Notes and News ............ 949

University and Educational News........ 952

MSS. intended for publication and books, etc., intended for review should be sent to the Editor of Scriscre, Garrison-onHudson, N. Y.

\section{SOME PRINCIPLES OF MUSEUM ADMINISTRATION}

IN No. 641 of ScIence (April 12, 1907) Dr. George A. Dorsey discusses in some detail the installation of the ethnological collections in the American Museum of Natural History, basing his criticism essentially on the point of view that the arrangement is an unsatisfactory attempt at popularizing the results of ethnological research. In his discussion he assumes that the essential object of a large museum must be research, not instruction, without, however, discussing the validity of this fundamental assumption.

I may be allowed in the following remarks to discuss what seems to me the vital question of the uses of museums as research institutions and as educational institutions. Since my own practical experience has largely been gained in ethnographical museums, I may be allowed to take my examples particularly from these, indicating at the same time in what respects ethnological museums seem to differ from natural-history museums.

Museums may serve three objects. They may be institutions designed to furnish healthy entertainment, they may be intended for instruction and they may be intended for the promotion of research.

The value of the museum as a resort for popular entertainment must not be underrated, particularly in a large city, where every opportunity that is given to the people to employ their leisure time in healthy and stimulating surroundings 
should be developed, where every attraction that counteracts the influence of the saloon and of the race-track is of great social importance. If a museum is to serve this end, it must, first of all, be entertaining, and try to instill by the kind of entertainment offered some useful stimulant. The people who seek rest and recreation resent an attempt at systematic instruction while they are looking for some emotional excitement. They want to admire, to be impressed by something great and wonderful; and if the underlying idea of the exhibit can be brought out with sufficient clearness, some great truths may be impressed upon them without requiring at the moment any particular effort. The visitor of this class does not go to the museum to study the exhibits case by case and to follow a plan carefully laid out by the curator, but he strolls through the halls examining something that attracts his attention here and there without much plan or purpose.

It is a fond delusion of many museum officers that the attitude of the majority of the public is a more serious one; but a calm examination of the visitors passing through museum halls shows very clearly that the majority do not want anything beyond entertainment. This can easily be proved by following them through the halls and listening to their remarks, by the general tendency of visitors to go through all the halls of the museums from end to end in order 'to have seen' the museum. It may be seen in the Sunday afternoon crowds in New York City when parents pass the hours after dinner with their children in pleasant surroundings, trying to take in the curious sights.

If this is true, then the very serious question arises, what can be done for this very large class of visitors? Obviously, a systematic exhibit will not appeal to them, and the best we can hope for is to bring home to them by single exhibits important points of view. Most of our museums are not built on a plan which promises success in this direction. To impress a point of view requires at least the possibility of concentration; while our large halls, built with a view to architectural impressiveness, do everything that is possible to distract the visitor, who, when just beginning to take in one exhibit, already looks forward to the next one, thus being prevented from ever concentrating his attention on any particular subject. Effectiveness must be based on the effort to concentrate attention, and on the unity of the idea expressed in each exhibit. Those who have seen the room in the Dresden $\mathrm{Mu}$ seum containing the Sistine Madonna will know what I mean. In this room is nothing to distract the attention of the visitor from the single exhibit, and consequently the room is a sanctuary.

It seems essential that before deciding upon the selection of subjects to be presented to the public, the museum director should be clear as to the objects to be obtained by popular exhibits. Popularization of science has become of late years a kind of Shibboleth, and we are only too apt to believe that an effort to present in a simple way results of scientific inquiry is in itself a praiseworthy endeavor.

I fear that in this belief some of the fundamental objects of the popularization. of science are overlooked. In the mass of lectures intended to popularize knowledge, in popular books, and not less in popular museums, intelligibility is too often obtained by slurring over unknown and ob-. scure points which tend to make the public believe that without any effort, by listen-. ing for a brief hour or less to the exposition of a problem, they have mastered it. This I consider one of the serious dangers of popular presentation of science. It is a stimulus to the overestimation of one's. 
own powers, which is so characteristic of many phases of our public life. It tends to stimulate the idea that the necessity for training for thorough work is an antiquated prejudice, and that good common sense with a little smattering of knowledge fits a man for any place in life, in business as well as in science and in public affairs.

What I understand by popularization of science is an endeavor to counteract these very influences, and to bring out the sublimity of truth and the earnest efforts that are needed to acquire it. Therefore every kind of inaccuracy should be most carefully avoided, and attempts to make all problems appear childishly simple by the elimination of everything that is obscure should not be tolerated.

This does not mean that the most complex problems should be selected for popular presentation, but the serious effort required to reach results should be emphasized. To apply this to the striking popular exhibits to which I referred before, enough should be given surrounding these exhibits to convey the impression that the visitor, by looking at the single thing, has not grasped all that is conveyed by the collections, and that there is more to study.

Another point of view should be borne in mind. When the technical perfection of the striking exhibits is very great, the danger is ever-present that the admiring public will not see the idea that is to be conveyed by the exhibit, but will forget even to look for it in its admiration of the technical skill exhibited in the installation. For instance, in an exhibit of gulls hovering over the waves of the sea, it is only too likely that the visitors will ask, "How are they suspended?' and that upon coming back from the museum, they will tell their friends of the skill exhibited in the invisible suspension of the birds, but presumably they will not know what birds they were. Thus every incidental point that is added to the essentials of the exhibit will distract attention from the fundamental idea. I fear that in some cases an interest in the artificial likeness to nature may be engendered like that felt by the courtiers of the Emperor of China in Andersen's fairy tale, 'The Nightingale,' when they all exclaim on discovering that the nightingale is not a mechanical toy: 'How uninteresting! It is a real bird!'

In order to attract the attention of the visitors who stroll through the halls, the museum needs a somewhat indifferent background of material, from which is set off here and there a striking exhibit intended to arrest attention; and the art of the museum administrator consists in the proper selection of such exhibits as will drive home a definite idea. A museum consisting only of an array of striking exhibits defeats to a certain extent its own ends, because where a great many objects of equal interest are assembled, the attention given to each is only slight. Furthermore, the indifferent background which consists of exhibits related to the one illustrating a particular idea elucidates the vastness of the problem dealt with, and is a check against the superficial assumption that the one exhibit exhausts the subject.

There are only two methods possible to reach the visitors who come to the museum to be entertained. The one is to have only a very few exhibits of rare beauty and excellence, which by their own merit will prove attractive. An attempt to carry this idea into execution has been made in parts of the Museum of the Brooklyn Institute. However; this is avowedly neither the object nor the method of a large museum which endeavors to gather under its roof a great variety of objects, and to impose not only by a small selection of ex- 
hibits, but also by the comprehensiveness of subjects presented. Wherever this is true, it must be recognized that it is impossible to hold the attention of the people by the whole mass of exhibits, but that for every visitor the bulk of the material must merely give the background from which some subject that happens to strike his fancy will stand out in bold relief.

I think the experience of all large museums shows that this point of view, so far as the general public is concerned, is the correct one. When, for instance, the installation of a new immense mounted skeleton of some extinct animal is announced, people will flock in crowds to the museum to see the specimen, and the receptiveness of their minds is increased by the whole mass of material from which the new impressive specimen is set off, and by the striking difference of the atmosphere in the museum as compared with the ordinary everyday routine. The same is true when a large, beautiful group of birds is exhibited. The impression, however, is quite different if the museum should contain a great many mounted skeletons of immense size, or a great many groups of birds of similar character. The visitors will pass from one to another, but the amount of impressiveness of each will be correspondingly decreased.

Considering this point of view, I think no word has ever been said that is less true than Dr. Brown Goode's oft-repeated statement that a museum is a well-arranged collection of labels illustrated by specimens. On the contrary, the attraction for the public is the striking specimen; and whatever additional information either the label or the surrounding specimens may be able to convey to the mind of the visitor is the only result that can be hoped for.

I believe experienced museum administrators will agree with me in thinking that among the museums having the best attendance, so far as it is not artificially increased by including the attendance of lectures among the museum visitors, this class of visitors amounts easily to ninety per cent. or more of the total number. This is true particularly of the United States National Museum, which is simply taken in as one of the sights of the national capital, and it is also true of the Saturday and Sunday attendance of a museum like the American Museum of Natural History in this city.

I am inclined to think that the museum can do a great deal towards public education by a judicious treatment of this aspect of its work; but it requires the highest talent to select and set off a striking object which brings home an important idea against the indifferent background so as to obtain the best results.

From the remarks that have been made, it will be seen that in a large museum opportunity is given to select objects in such a way that a great variety of important points of view are brought out by special exhibits.

An attempt of this kind has been made, in the large entrance-hall, a number of very excellent exhibits are arranged, partly of a systematic character, partly intended to bring out certain special biological points. I believe the feeling that is conveyed here upon the visitor is a very favorable one, in so far as the assemblage of this material in the entrance has for its background the expectancy created by the mass of material to be found when the visitor moves from this hall into the galleries of the building. On the other hand, it may be said that still better results might be had if these halls themselves were to contain here and there equally striking exhibits.

I believe the appreciation of the needs of the visitor who wants to be entertained has led most museums to lay much stress upon the preparation of groups in which certain objects are brought together, and which are generally intended to illustrate 
some important point. In the practise of group-making that has developed during the last fifteen years the need of the class of visitors for whom they are intended is often lost sight of. A group does not convey any more information than a picture in an ordinary picture-book might be made to convey. It differs from the picturebook in being more impressive by its size and surroundings. Therefore a series of groups, all of which illustrate different aspects of the same idea, are undesirable, because the impressiveness of each is decreased by the excessive application of the same device. I believe the effect of this undue multiplication of groups of the same type may be noticed in the collections of the United States National Museum. It is true that the multiplication of groups in the anthropological department of that museum is not due to a systematic endeavor on the part of the administration to present every Indian type in the form of a group. It is due rather to the onerous duty imposed upon the museum to send some new striking exhibit to every one of the endless series of national and international expositions, which, of course, are seen almost exclusively by sight-seers, who can not be reached by anything but such large exhibits as groups. Any one who will observe the visitors of the United States National $\mathrm{Mu}$ seum strolling through the Catlin Hall, which contains the Indian groups, will readily see how the first group seems very interesting, and how quickly the others appear of less and less interest and importance. For this reason it may safely be said that the method of bringing together large exhibits should be employed only sparingly, and that the effect of each of these exhibits will be the greater the better it is set off against an indifferent background.

I have mentioned here large exhibits as those which will attract the general public.
This is not quite correct, in so far as there will always be an appreciable number of visitors of a higher education, who may be attracted by the beauty and compact idea brought out by small special exhibits.

Museums may also be employed for the purpose of imparting systematic information. The number of people who visit the museum in search of such information is, comparatively speaking, small, but not by any means negligible; and the duty of the museum to supply such information to those who are in search of it must not be questioned. The question arises, however, in how far a very large museum is capable of supplying the needs of students of this type. Assuming a building like the Amer: ican Museum of Natural History, which has at present eighteen halls and six galleries, with a floor space of from eight to ten thousand feet for the halls, and of from four to five thousand feet for the galleries, and imagining the various halls so arranged as to give a systematic presentation of the various sciences, we find that the whole becomes such a maze of separate and intercrossing systems, that the average visitor, even if desirous of obtaining systematic information, would be frustrated by the mass of material presented.

Here, obviously, the fundamental principle of elementary education has to be applied; namely, that effectiveness does not lie in diversity, but in the thoroughness of the material presented. Multum, non multa. So far as I am aware, the attempt at systematizing the collections of a very large museum according to a rigid scheme has never been made, obviously on account of the insuperable difficulties that present themselves.

One of these difficulties consists in the lack of systematic collections illustrating all the different branches of science. This lack is very striking in all our American 
museums, where the mass of material consists almost everywhere of collections from North America, and where material from other continents is very inadequately represented. There is no inherent difficulty in obtaining small systematic collections covering any particular branch of science, but in a large museum there is always a preponderance of material relating to particular problems or to particular regions. This lack of material will always be an obstacle to a complete systematization of large collections, even if such systematization were desirable. A number of small museums have tried to develop representative and systematic collections, with excellent success, and have become in this way important adjuncts for the teaching facilities of the cities in which they are located; but here efficiency is inseparable from small size.

The difficulties that lie in the way of arranging a large museum according to a systematic plan of instruction are manifold. First of all, it must be recognized that in a large city people with entirely different interests will consult the museum, and will therefore desire to find the material in entirely different systematic arrangement. To take the example of zoology. One teacher may desire to utilize the museum for his classes in which he gives a review of systematic zoology. Another one may desire to impress upon the student the development of the nervous system or of certain organs of the body. Still another may be interested in the essential phenomena relating to the question of evolution of species. And still another may want to illustrate by means of collections the traits of local faunas. The greater the number of people who desire to consult the museum in this manner, the more numerous will also be the points of view from which systematization will appear desirable. I think even to those not familiar with museum administration it will be at once apparent that the attempt to organize the entire collections of a large museum from this point of view can have only one result. If every justifiable point of view is included, the complexity of the system will become so great that the usefulness of the whole series will become very doubtful. If, on the other hand, only a few points of view are selected, then all sciences as presented in that particular museum will appear in the strait-jacket into which they have been put by the narrowness of the selected view-points, while the material should rather be so arranged that it can be grasped from a multitude of points of view.

The experience of school museums and of university museums points clearly the way in which this difficulty may best be solved. A large museum might have a wing or a small group of halls set aside for the purpose of systematic instruction, where classes could be taken from one case to another, and where the essential points of view which are used in the ordinary teaching of science are utilized as the principle of installation; but the usefulness of these halls should not be overestimated, because the museum, with its mass of exhibits, is not a favorable place to obtain concentration of attention of students. That much can be attained in this manner by a small museum, and with very slender means, is shown, for instance, by the museum in Salem, Mass., which, with an annual appropriation of $\$ 8,000$ (including all salaries, maintenance and purchases), has, under the able direction of Professor Edward S. Morse, done much for public education.

In cities of the size of New York or Chicago or Philadelphia, the best use of such a centralized collection can not be made. On account of the enormous distances in the city, it will very seldom be possible to assemble at any definite time in the museum 
a group of students who might profit by a collection of this kind. Furthermore, the collection, once installed in a large museum, and intended to serve teaching interests scattered all over the city, must necessarily be more or less stationary-and the more so, the more money is expended on excellence of installation-and can not be adapted to the needs of different schools. For this reason the system which is used in many schools, of having separate school museums which are intended to serve this purpose, is infinitely preferable, and renders entirely unnecessary the attempt to make a large institution serve primarily the demands of school classes.

To take again the example of the American Museum of Natural History, I believe it is claimed by the administration of that museum that the systematic arrangement of collections assists the public schools, and that the large appropriation which the museum receives from the city is largely justifiable for this reason. The appropriation amounts, I believe, to nearly two hundred thousand dollars annually, while the buildings without grounds represent an approximate value of three million dollars. If we imagine that only one third of this annual appropriation were used for the maintenance of school museums, and that instead of the single large complex of buildings, twenty small museum buildings were established in various parts of the city, these ends would be infinitely better subserved, and the central museum-that is, the American Museum of Natural History-would be relieved of a duty which it tries to perform, but which, owing to the very size of the institution and of the city, it can not fulfil. Such small museums would have the same relation to the main museum, that the branches of the public library have to the central library, which, through this agency, has increased its educational usefulness many times, and has diverted a certain class of demands from the central library into other channels better able to meet them.

It would be an excellent plan if that museum and others similarly supported were required to furnish school museums with the necessary material and information, leaving to the teachers of the schools the free use of the specimens, for no printed label can take the place of the freedom of selection of specimens, picked out by the teacher as occasion may arise in the course of his instruction.

For a great many years attempts have been made in France and Switzerland, and these have recently been repeated in America, to arrange small collections for publicschool use, and to send these about from school to school. This attempt deserves every encouragement, although here also in our large New York schools there will be ample opportunity for the use of specimens to justify the establishment of small permanent school collections, which will be found much more economical than the con stant transportation of museum material from place to place, and which may be purchased at fairly reasonable rates from dealers in teaching-material.

Even if such school museums were established, it would still be justifiable, and perhaps desirable, for the museum to maintain a few halls intended for systematic instruction; but if museums are to serve only educational purposes, then large museums are not only unnecessary, but even undesirable.

The same objections that may be raised against the wholesale elimination of large collections from the exhibits, and the retention of striking exhibits only, should also be raised against the schematization of museum material. Nothing perhaps helps more to convey the idea of completeness and of the uselessness of further effort than the presentation of a whole museum as a 
complete finished exhibit, in which everything has its place in a definite system. Such a museum will fail to bring home the complexity of nature and an appreciation of the efforts required for a mastery of its secrets.

The impossibility of basing museum installation on a classification of objects from a single material point of view can be made clear best by the example of anthropological exhibits. At the same time this consideration will show in what the difference between anthropological collections and natural-history collections consists. An assemblage of material such as is found in anthropological collections consists entirely of things made by the various peoples of the world-their tools, household utensils, their ceremonial objects, etc. All of these are used in the daily life of the people, and almost all of them receive their significance only through the thoughts that cluster around them. For example, a pipe of the North American Indians is not only a curious implement out of which the Indian smokes, but it has a great number of uses and meanings, which can be understood only when viewed from the standpoint of the social and religious life of the people. It even happens frequently in anthropological collections that a vast field of thought may be expressed by a single object or by no object whatever, because that particular aspect of life may consist of ideas only; for instance, if one tribe uses a great many objects in its religious worship, while among another, practically no material objects of worship are used, the religious life of these tribes, which may be equally vigorous, appears quite out of its true proportions in the museum collections. Another reason, namely the natural destruction of material, makes it quite impossible to make archeological collections systematic. Thus it happens that any array of objects is always only an exceedingly fragmentary presentation of the true life of a people. For this reason any attempt to present ethnological data by a systematic classification of specimens will not only be artificial, but will be entirely misleading. The psychological as well as the historical relations of cultures, which are the only objects of anthropological inquiry, can not be expressed by any arrangement based on so small a portion of the manifestation of ethnic life as is presented by specimens. Any one who has grasped this truth will recognize at once that an anthropological exhibit can not be cast into the single schematic mold which is to be repeated automatically the world over for every single people. With the wealth of interesting and important problems of anthropology, it is, however, perfectly easy to bring out in a popular manner one salient point here, another salient point there, according to the characteristics of the life of the people dealt with.

The difference between anthropological exhibits and those relating to natural sciences is only one of degree, because in no case do specimens alone convey the full idea that a collection is intended to express. This is particularly true in any exhibit intended to express function rather than form; as, for instance, in exhibits illustrating dynamic geology or facts relating to the physiology of plants and animals. The difference between anthropological and natural-history collections, however, consists in the trifling importance of the specimens as compared with their functional importance in anthropology, and to the fact that all the specimens are primarily incidental expressions of complex mental processes that are themselves the subject of anthropological inquiry. These latter are almost entirely missing in that field of biology which is ordinarily presented in museums. 
For this reason anthropological collections should be treated like collections of artistic industry and art collections rather than like collections illustrating natural sciences.

It is therefore clear, that, so far as the public is concerned, the essential point of view of the anthropological collection and that of the natural-history collection are entirely distinct; and, if the attempt is to be made to bring out coherently the ideas underlying the anthropological exhibit, there ought to be no necessity for the visitor to come into contact with the natural-history exhibits while passing through the anthropological halls. On the whole, this end is difficult to attain in a large complex museum building; and the question may therefore be very well raised, whether it would not be better to separate entirely anthropological collections from those relating to natural history.

Still another consideration may be mentioned here, which has an important bearing upon the systematic arrangement of anthropological collections. It has been pointed out before that anthropology is essentially an historical science, and consequently not readily amenable to systematization; but, further than this, there is so much disagreement among the best anthropologists of our times in regard to the significance of anthropological data in a systematic presentation of the subject, that it seems hardly justifiable for any museum to assume to dictate by its arrangement what the approved system of anthropological science shall be.

Before further discussing the question of museum policy in regard to its relation to the public and to schools, it may be well to discuss the value of the museum as an institution intended to serve the progress of science.

The objection which is raised against the concentration of the work of the large museum in these lines rather than in educational lines is the old objection against serving the few rather than the masses. Serious educators have long since recognized that the education of the masses which we all desire is impossible without the most thorough and painstaking educa. tion of the teacher, and that the applicability of a sound educational system can not be confined to elementary schools, but that without secondary schools, colleges, universities and training schools for teachers, the whole system of public education falls to the ground. Therefore, we do not at all agree with the popular illusion that opportunities given to the few who advance science are opposed to the advancement of the masses, but we rather recognize in them an indispensable means of advancing public education.

I do not hesitate to say that the essential justification for the maintenance of large museums lies wholly in their importance as necessary means for the advancement of science. This is particularly clear in the case of the United States National Museum, which is the depository of all the government surveys, and whose duty it is to preserve the material on which the work of the surveys is based. The education of the masses can be infinitely better subserved by small museums.

What, then, is the function of the large museum? It is the only means of bringing together and of preserving intact large series of material which for all time to come must form the basis of scientific inductions. Every year shows more clearly that the loss of old collections, due to the lack of large museums until the middle of the last century, is one of the serious obstacles to the advancement of science. Museums are the storehouses in which not only must the material be preserved by means of which deductions of scientists can 
be checked, but they are also the place where scientific materials from distant countries, vanishing species, paleontological remains, and the objects used by vanishing tribes, are kept and preserved for all future time, and may thus be made the basis of studies which, without them, would be impossible. We are spending vast sums year after year to bring together evidences of life forms of distant countries and of past ages, to accumulate the monuments of the past and objects used by remote tribes. We collect these because they are the foundation of scientific study. Should we then be unwilling to provide adequate means for keeping intact the results of our expensive inquiries? It is the essential function of the museum as a scientific institution to preserve for all future time, in the best possible way, the valuable material that has been collected, and not to allow it to be scattered and to deteriorate.

Considering this point of view, there can be no greater misconception of the duties of a museum administrator than the belief that proper care of accumulated material is less important than beautiful exhibits. The lack of proper care of inflammable and perishable material, the constant shifting about of material not used for exhibits, the lack of conservatism in exchanging and giving away collections for elementary educational purposes, belong to the most inexcusable features of museum administration. Unfortunately the method of preservation of collections in our museums is in many cases not what it ought to be, partly from necessity, partly from choice. The crowded condition of the building, like that of the United States National Museum, or the attempt to relegate vast amounts of material to storagerooms, as in the American Museum of Natural History, and the use of wooden receptacles for the storage of valuable material, endanger the safety of the collec- tions and make their use temporarily or permanently difficult. Serious scientists know perfectly well that in the study of biological and anthropological phenomena observations on a single specimen are generally misleading, and that one of the great advantages gained in modern times, and based to a great extent upon the improvement of museum methods, consists in the possibility of examining long series rather than individuals. The reason for this is that the series alone can give us what is characteristic, while, when only an individual is available, characteristic traits may be overlooked, or we may be liable to consider an accidental trait as characteristic for a whole group. For this reason science is better served by the preservation of large series relating to the same question in one place rather than by scattering such series over a great many different places. This is true of all sciences, and this is the justification for the accumulation of extended material bearing upon the same point. Inroads that are made upon large collections in order to obtain scattering material otherwise not represented in the museum should be resisted by every conscientious scientist.

In order to make large series useful, the bulk of the material in a museum should be kept in such a manner that it is not only accessible at a moment's notice, but that it can also be examined from any point of view. While in zoological collections consisting of skeletons and skins, this end may be attained fairly adequately by storage in metal boxes systematically arranged and easily opened, other material can not be handled in the same manner. This is particularly true of anthropological material, which, on account of the difference in size, form and material of the objects, and on account of the multiplicity of the points of view from which the material can be viewed, can only be stored 
satisfactorily in such a way that each specimen can be seen.

I do not consider it necessary to discuss in greater detail the functions of the large museum as an agency in promoting science, because there can be little difference of opinion in regard to this question. Wherever investigations are undertaken that are based largely upon specimens needing preservation, the work is necessarily undertaken by a museum or by institutions closely affiliated with museums. It may be pointed out, however, that the strong tendency to accumulate specimens has often been a disadvantage in the development of anthropology, because, as was pointed out before, there are many aspects of this science in which the material objects are insignificant as compared with the actual scientific questions involved.

The experience of institutions like the Field Museum of Natural History and the United States National Museum shows clearly that the necessity of accumulating collections practically excludes important aspects of anthropological work from the field of museum activity. In former times the American Museum of Natural History followed a more liberal policy in this respect, while at present the broader point of view seems to be gradually becoming recognized in the Field Museum; but the rapid changes of policy through which these institutions have passed show that anthropology requires a broader point of view for its field-work than that offered by the strict requirements of the acquisition of museum specimens. The only institution in which the necessary freedom is offered is the Bureau of American Ethnology, which is not hampered by any requirement of accumulating specimens through its investigations.

This same point of view brings it about that museums of natural history are liable to lay much greater stress upon systematic zoology and botany than upon detailed anatomical study, the results of which can not be exhibited equally well, and that the study of functional traits is hardly ever attempted, because it offers still greater difficulties to the exhibitor.

So far as the scientific administration of museums is concerned, the principal problem is that of the extension of museum activities so as to overcome the limitations set by the tendency to acquire a considerable number of specimens.

I believe that among American museum administrators Professor F. W. Putnam deserves the highest credit for having been the first to recognize the limitations of the activity of the museum if restricted entirely by the desire for the acquisition of specimens, and for having courageously set to the museum scientific problems selected in accordance rather with their scientific importance than with the probability of yielding many specimens.

Bearing these points in view, the question arises, in how far the interests of the public and the interests of science can be harmonized. It is my opinion that the attempt at a thorough systematization of a large museum must be given up, because it is based upon a misconception of the function of the large museum. Systematic museums must be small museums.

It is very probable that in a large museum in which the systematization of the exhibit for the benefit of educational purposes is made the principal point of view the function of the individual curator will become more and more that of an officer who carries out the orders received from the general museum administration, so that there would hardly be room for investigators of the highest order in such an institution. That the systematization and popularization of the collections of a large museum does not agree with the best interests 
of science, has evidently been felt by the administration of the United States National Museum, in which, in the Biological Department, the work on the exhibit halls has been divorced completely from the scientific work on the collections.

The question then arises, What shall we do with our collections to make them useful to the public and at the same time useful for the advancement of science? Two methods are possible for reaching this end. Either we may have a complete separation of the collections intended for the public and of those intended for the scientist, or we may decide to make the entire collection equally accessible to the public and to the scientist.

Reasons may be brought forward in favor of either method, and it is largely a question of economy what method shall be pursued. The method adopted will also determine the form of the museum building. Unfortunately this point of view is seldom considered in planning museum edifices. Taking the example of the American Museum of Natural History, we find the whole museum, with the exception of the cellar and the top floor, which is a halfattic, laid out in large magnificent halls, which, of course, means that the whole museum is to be accessible to the public. Consequently there is no choice but to subserve in the exhibits both the aims of the scientist and those of the general public. The proportional amount of space available for storage in a building of this kind is so small that full use of the stored material for scientific purposes is entirely out of the question. The opposite point of view has been followed in the Zoological Museum in Berlin, one of the very few buildings in which the deliberate attempt has been made to separate exhibit collections from study collections. Here, however, the space allotted to the study collections is more than twice as large as the space allotted to exhibit collections.

If a museum is planned like the American Museum of Natural History, the only thing to do is to acknowledge freely that the public is to be admitted to all the collections in the museum; to arrange the collections from scientific points of view, and to set off from these collections in conspicuous places those exhibits which are intended for the public. The central aisles of the large halls, for instance, lend themselves admirably for exhibits of this type, while the side alcoves may be used to furnish the indifferent background from which the popular exhibits should be set off.

I am not by any means convinced that this is the best solution of a difficult problem. The attempt to make accessible in this way the entire collections is unnecessarily expensive; and the work that must go on in the collections, if the museum is to be a live institution at all, will tend to distract from the dignity of the halls, which I consider, so far as the public is concerned, as one of the essential features of the museum. It seems to me that while the public is admitted to a museum hall, everything in the hall should be calculated to increase the impression of dignity and of aloofness from every-day life. No dusting, no mopping, no trundling-about of boxes, should be permitted in a hall visited by the public, because it disturbs that state of mind that seems best adapted to bring home the ideas for which the museum stands.

It has been proposed to overcome the economic difficulty involved in the necessity of having large collections accessible, and the expensiveness of exhibit halls intended for the public,- by placing the study collections outside of the large cities, in suburbs, where land is inexpensive, and where unpretentious buildings can be erected. This 
proposition has been made in England, and has been carried out by the Ethnographieal Museum in Berlin. Although the separation of the exhibit collections and the storage collections involves considerable administrative difficulties, and is open to scientific objections, it is not impossible that we shall necessarily be led to the adoption of this principle of administration. While, however, the collections are concentrated in one large building, we must accept the principle that the collections must receive proper care, and must be available for scientific study. In our museum buildings with which we have to get along at the present time, this end might very well be attained by placing either in one wing or on one floor the exhibits intended for the general public, and also those intended for students in high schools, special training schools, colleges, and even for many students of universities. In collections of this kind the more advanced collections intended for students would give what I called before the indifferent background which is so necessary for the general public. A large number of halls, however, will have to be installed in a more condensed manner, perhaps by adding galleries to halls of unnecessary height, in which material could be made accessible to students. There is no reason why the public should not be admitted to halls of this kind, although presumably very few of the visitors would carry away any other impression than that of the magnitude of the field of work covered by the museum. A thorough reorganization of museum administration will not be possible until the plan of operation of the museum is decided upon before the museum building is erected, and until the small systematic educational museum, which serves as an adjunct to elementary instruction, is separated entirely from the large museum. Like the university, the large museum must stand first and last, in its relation to the public as well as in its relation to the scientist, for the highest ideals of science.

Franz Boas

\section{SCIENTIFIC BOOKS}

THE COLLECTED WORKS OF GEORGE WILLIAM HILL

THE Carnegie Institution of Washington has already undertaken many forms of scientific activity during the short period of its existence. These may be divided into two classes. First, the cases where it assists science indirectly by a grant to an individual for the prosecution of some piece of work which might or might not be done without this aid; and second, the cases where some particular branch of knowledge is to be advanced or assisted by expenditure on lines which will not benefit any individual in particular, either in money or in reputation. There is considerable doubt whether an ultimate gain is to accrue to the scientific world from the former method: the danger of pauperizing research is a matter which can not be regarded lightly, for the most notable contributions have more frequently been made by those who have done their work in spite of difficulties and who, under an easier régime, would not have felt the need for exertion. Little criticism can be made on the second class of cases, where organization and a large equipment is frequently required. The routine work involved in making or collecting or publishing huge masses of data is often neither possible for an individual nor stimulating to any one who is obliged to undertake it for some definite object which he may have in view.

To the second class belongs some of the work that may be done by a publishing house whose sole concern is not the maximum financial gain to be extracted from its operations. Of this there already exist excellent English examples in the Pitt Press at Cambridge and' the Clarendon Press at Oxford. It is true that these businesses are run on a commercial basis in so far as they publish books which appeal to a large circle, but they also issue works on which a considerable financial loss is expected, so that the net annual profit is not 